Check for updates

Cite this: RSC Adv., 2019, 9, 3828

Received 16th December 2018 Accepted 14th January 2019

DOI: $10.1039 / c 8 r a 10319 d$

rsc.li/rsc-advances

\section{Study of the perpendicular self-assembly of a novel high- $\chi$ block copolymer without any neutral layer on a silicon substrate}

\author{
Baolin Zhang, (D) ab Weichen Liu, ${ }^{\mathrm{b}}$ Lingkuan Meng, (D) *cd Zhengping Zhang, ${ }^{\mathrm{a}}$ \\ Libin Zhang, ${ }^{\mathrm{b}}$ Xing Wu, ${ }^{\mathrm{e}}$ Junyan Dai, ${ }^{\mathrm{e}}$ Guoping Mao ${ }^{\mathrm{e}}$ and Yayi Wei ${ }^{* \mathrm{~b}}$
}

\begin{abstract}
A novel type of high- $\chi$ block copolymer, polystyrene-block-polycarbonate (PS- $b-P C$ ), which contains an active $-\mathrm{NH}$ - group on the polymer backbone between the PS block and the PC block, has been successfully synthesized. Vertical micro-phase separation can be successfully achieved on Si substrates with neutral-layer-free materials with a pitch of $16.8 \mathrm{~nm}$. Water contact angle experiments indicate that PS and PC have approximate surface energy values on Si substrates. A hydrogen bond mechanism has been proposed for the formation of a periodic and lamella-forming phase separation structure, with the domains oriented perpendicular to the substrate. A combination of both theory and experimental verification proves that the hydrogen bonding plays a dominant role as a real driving force to promote vertical micro-phase separation in the absence of a neutral layer. Subsequently, the study of a novel block copolymer on four different types of substrate without any neutral layer further confirms that the newly synthesized material enables greater flexibility and potential applications for the fabrication of various nanostructures and functional electronic devices in a simple, cost-effective and efficient way, which is of considerable importance to contemporary and emerging technology applications.
\end{abstract}

\section{Introduction}

Recently, interest in the patterning of self-assembly of block copolymers (BCPs) has attracted considerable attention because of their wide and promising applications in many fields of nanoscience and nanofabrication, including biomolecule detection, ${ }^{\mathbf{1}}$ nanochannels for nanofluidic fabrication, ${ }^{2}$ nanostructure fabrication, ${ }^{3,4}$ advanced IC devices, ${ }^{5,6}$ and as a nanoimprint template to create nanopillars. ${ }^{7,8}$ These potential applications have driven extensive efforts in both academia and industry to apply the technique to achieve precisely controlled geometric size, highly aligned and ordered arrays to meet the stringent requirements for many emerging applications, especially in semiconductor IC manufacture and fabrication of some functional electronic devices. With the shrinking of the size of

${ }^{a}$ College of Big Data and Information Engineering, Guizhou University, Guiyang 550025, P. R. China

${ }^{b}$ Integrated Circuit Advanced Process Center (ICAC), Institute of Microelectronics of Chinese Academy of Sciences (IME CAS), Beijing 100029, P. R. China. E-mail: weiyayi@ime.ac.cn; Fax: +86-10-82995684; Tel: +86-10-82995898

'The Integrated Circuit Materials \& Components Industry Technology Innovative Alliance, 27 Zhichun Road, Haidian District, Beijing 100083, P. R. China. E-mail: lingkuan_meng@icmtia.com; Tel: +86-10-82357517

${ }^{d}$ School of Electronic Engineering, Chengdu Technological University, Chengdu 611730, P. R. China

ejiangsu HanTop Photo-Materials Co., Ltd, Floor 4-5, Buliding No. 9, No. 1158 Zhongxin Rd, Shanghai, P. R. China semiconductor devices, the traditional $193 \mathrm{~nm}$ immersion lithography combined with multi-patterning technology is becoming more and more complicated in $10 \mathrm{~nm}$ nodes and beyond. This is bound to require a novel lithography solution, such as EUV (extreme ultraviolet lithography), DSA (directed self-assembly) technology, etc. Self-assembly of BCPs combined with advantages of conventional photolithography and polymeric materials shows a great utility for semiconductors and a lot of potential applications. It does not require an optical exposure system and reticles, and therefore it is very costeffective and attracts lots of interest. It is currently considered as a promising alternative patterning technology to extend Moore's Law for future nodes by ITRS (International Technology Roadmap for Semiconductors). In order to apply self-assembly of BCPs in semiconductor manufacture, effective micro-phase separation must be achieved. For example, lamellar phase separation BCPs can be used to fabricate fin and gate arrays in advanced FinFET devices., ${ }^{\mathbf{9} 10}$ Vertical cylinder phase separation can be used to make contact holes or channel holes in advanced CMOS devices. ${ }^{11,12}$ The self-assembled, periodic structures of BCPs with well-defined sizes and separation distances on the tens of nanometers length scale or even a few nanometers have been recognized as a promising route for the fabrication of a wide range of functional nanostructures. By changing molecular weight, chemical structure, molecular architecture, and composition of BCPs, the size and type of self-assembly can be controlled precisely. Understanding and controlling the 
orientation and/or dimensions of BCP microdomains are very essential for various advanced device applications.

Most research on the vertical phase separation of BCPs has been focused on utilizing neutral layers to realize a surface energy balance between blocks on the substrate. The neutral layer is a random copolymer that exhibits a similar surface to both blocks, and it is spin-coated on the substrate before applying the DSA material. The neutral layer covers the substrate and neutralizes the chemical property of the substrate surface for the target DSA materials. In general, different DSA materials require different neutral materials and thicknesses to control surface energies, and therefore to accurately control the phase separation structures. Poly(styrene-block-methyl methacrylate) (PS- $b$-PMMA), which consists of two monomers (PS and PMMA), is the most popular BCP in semiconductor fabrication for its good compatibility. After annealing, the blocks in the BCP phase-separate from each other and self-assemble into the most energetically favorable nanostructures. ${ }^{13}$ By directing these small nanopatterns, highly uniform and highly ordered line/space or hole arrays can be obtained and then can be used as etching masks in the fabrication of various nanostructures. ${ }^{\mathbf{1 4 - 1 7}}$ Both industry and academia have done much research on the micro-phase separation of BCPs with neutral layers and the correlation of the neutral layer components. ${ }^{18}$ For example, Nealey's research group has conducted some detailed studies on various aspects of materials and process conditions for neutral and BCP layers. ${ }^{19,20}$ Russel and Hawker et al. have also conducted a lot of research on BCPs with neutral layers. ${ }^{21-26}$ In et al. have studied the effect of the positions of the functional group positions on the properties of the neutral layer. ${ }^{27}$ Better neutralization effect is observed when hydroxyl groups are located on side chains compared with those on chain ends. Random copolymers with side-chain groups are widely used as neutral layer materials. Han et al. studied three different neutral materials, and how a change in their compositions impacts phase separations. ${ }^{28,29}$ In addition to the selection of effective neutral layer materials, various process conditions have also been explored to maximize the neutralization effects; for example, curing the neutral layer molecules by UV radiation. ${ }^{30}$

However, micro-phase separation using a neutral layer requires many complex process steps, complicated processes, high experiment costs, etc. ${ }^{31}$ Consequently, it would be preferable to have a self-assembly process with no neutral layer. Fewer materials mean lower cost and reduced process steps, and thus low defects and high yields.

Recently, researchers at IBM have reported a series of BCPs with fluorine ion $\left(\mathrm{F}^{-}\right)$in between the two blocks of each BCP. ${ }^{32}$ The $\mathrm{F}^{-}$ion which has low surface energy can effectively wet a neutral layer, form preferential adhesion on the neutral layer, and lead to a good vertical phase separation for its low surface energy. ${ }^{33,34}$ However, due to the use of the weak $\mathrm{F}^{-}$in the BCP, the molecular weight is relatively large, resulting in the formation of a larger phase separation period. Moreover, the thermal annealing temperature applied is high and the self-assembled phase separation also requires a range of process conditions, such as a neutral layer or other surface coatings, which pose many difficulties and challenges for whole process development.
Based on the above considerations, development and research of new BCPs with no neutral layer are of critical importance. In this work, a novel diblock copolymer, polystyrene-block-polycarbonate (PS- $b$-PC), which contains an active -NH- group in between the PS and PC blocks, with low surface free energy has been successfully synthesized. The - NH- group can help to achieve effective micro-phase separation in the absence of a neutral layer on silicon substrate. Meanwhile, the role and function of $\mathrm{H}$-bonding in micro-phase separation are comprehensively explored. Besides silicon substrate, the novel PS- $b$-PC copolymer also exhibits great potential on some other silicon-based substrate materials such as $\mathrm{SiO}_{2}$ and $\mathrm{Si}_{3} \mathrm{~N}_{4}$. The approach shows some obvious advantages such as simple process, low cost, large-scale formation on a substrate and a potentially high degree of frequency multiplication compared with some previously published works.

In this paper, the present section mainly includes a detailed problem description encountered in self-assembly study, and then clarifies the motivation of our work presented and briefly explains what the work intends to do. Section 2 offers some details of the phase separation experiments, including copolymer synthesis, raw materials and synthesis conditions described here. Section 3 presents the results and discussion, including experimental characterization, theoretical and mechanism analysis, experimental verification and a few potential applications on four different silicon-based substrates. Finally, Section 4 provides a brief conclusion. The results reported herein significantly help advance our understanding of self-assembly of the novel BCP.

\section{Experimental}

\subsection{Preparation of novel block copolymer (PS-b-PC)}

(1) Materials. The styrene monomer was purified by alumina in order to remove the inhibitor. Copper(I) bromide $(\mathrm{CuBr})$ was stirred at room temperature with glacial acetic acid followed by methanol and diethyl ether wash. Dichloromethane (DCM) was stirred with $\mathrm{CaH}_{2}$, after which the solution was filtered and sealed.

(2) Preparation of macro-initiator PS-Br. Styrene (20 g, $192.03 \mathrm{mmol}$ ) and anisole $(5 \mathrm{ml})$ were mixed and stirred. After vacuum evacuation three times with argon protection, copper(I) bromide (0.55 g, $3.83 \mathrm{mmol})$ and ligand (0.66 g, $3.81 \mathrm{mmol})$ were added. The mixture was stirred for about 20 minutes, and then the initiator $(0.70 \mathrm{~g}, 3.78 \mathrm{mmol})$ was added. The new mixture was heated to $105{ }^{\circ} \mathrm{C}$ along with argon gas protection. After $1.5 \mathrm{~h}$, the flask was placed in dry ice to stir and cool. The reaction solution was first precipitated in methanol and then dried at $40{ }^{\circ} \mathrm{C}$. After that it was dissolved in tetrahydrofuran (THF) to obtain a $20 \mathrm{wt} \%$ solution.

(3) Preparation of macro-initiator PS-NH- $\left(\mathrm{CH}_{2}\right)_{2}-\mathrm{OH}$. Polystyrene with bromine end groups $\left(M_{\mathrm{n}}=3900, M_{\mathrm{w}} / M_{\mathrm{n}}=\right.$ 1.22) was reacted with 10 equivalents of 2 -aminoethanol in the presence of triethylamine solvent at room temperature for 48 hours. The product was precipitated in $\mathrm{MeOH}$ for some time, and then re-dissolved in THF to obtain a $20 \mathrm{wt} \%$ solution at certain condition. 
Table 1 PS- $b$-PC film self-assembly process parameters

\begin{tabular}{llll}
\hline No. & Process name & Equipment & Process parameters \\
\hline 1 & Substrate cleaning & Cleaning tank & SPM, $120{ }^{\circ} \mathrm{C}, 10 \mathrm{~min} ; \mathrm{APM}, 65{ }^{\circ} \mathrm{C}, 10 \mathrm{~min}$ \\
2 & Copolymer spin coating & Gluing machine & PS- $b-\mathrm{PC}$ with solid content $(1 \%)$ solution, $0.8 \mathrm{ml}, 500 \mathrm{rpm} / 5 \mathrm{~s} ; 1500 \mathrm{rpm} / 30 \mathrm{~s}$ \\
3 & Copolymer spin coating & Vacuum oven & Vacuum, $140-190{ }^{\circ} \mathrm{C}, 10 \mathrm{~min}$
\end{tabular}

(4) Preparation of block copolymer PS-b-PC. In a four-neck flask, $10 \mathrm{~g}$ of PS-OH containing active $\mathrm{H}$ was added, and then TMC (12 g, $117.43 \mathrm{mmol})$ and DCM $(10 \mathrm{ml})$ were added. The reaction mixture was stirred until the macro-initiator and TMC were completely dissolved in DCM. After that, DBU (0.2 g, 1.32 mmol) was added to react for $7 \mathrm{~h}$ at $30{ }^{\circ} \mathrm{C}$. And then DCM $(10$ $\mathrm{ml})$, acetyl chloride $(2 \mathrm{~g}, 25.48 \mathrm{mmol})$ and triethylamine $(2.5 \mathrm{~g}$, $25.64 \mathrm{mmol}$ ) were added to react for $2 \mathrm{~h}$. After precipitation and fractionation, the novel BCP material with narrow dispersity was obtained. $M_{\mathrm{n}}(\mathrm{GPC})=7.0 \mathrm{k}, M_{\mathrm{w}}=8.1 \mathrm{k}, \mathrm{PDI}=1.157 . M_{\mathrm{n}}$ $(\mathrm{NMR})=\mathrm{PS}(3.9 \mathrm{k})-b-\mathrm{PC}(2.0 \mathrm{k})$.

\subsection{Phase separation experiments}

The silicon wafer used in this study was $100 \mathrm{~mm}$ in diameter, with p-type doped (100) plane. The wafer was cleaned with sulfuric acid and hydrogen peroxide mixed solution (SPM, $7: 3$ ) at $120{ }^{\circ} \mathrm{C}$ for $10 \mathrm{~min}$, followed by ammonium hydroxide and hydrogen peroxide mixed solution (APM, $1: 2: 5$ ) at $65{ }^{\circ} \mathrm{C}$ for $10 \mathrm{~min}$. And then the hydrophobicity of the samples was characterized by a contact angle instrument. The whole process flow is summarized in Table 1.

\subsection{Deposition of four different substrates}

The substrates of silicon dioxide $\left(\mathrm{SiO}_{2}\right)$ and silicon nitride $\left(\mathrm{Si}_{3} \mathrm{~N}_{4}\right)$ were deposited by plasma-enhanced chemical vapor deposition (PECVD) using a TRION PEWD Minlock. The film thicknesses of $\mathrm{SiO}_{2}$ and $\mathrm{Si}_{3} \mathrm{~N}_{4}$ were both $40 \mathrm{~nm}$. A $30 \mathrm{~nm}$ thick $\mathrm{Si}_{3} \mathrm{~N}_{4}$ film was deposited over a bulk silicon substrate followed by a $40 \mathrm{~nm}$ thick $\mathrm{SiO}_{2}$ material using PECVD. Similarly, a $30 \mathrm{~nm}$ thick $\mathrm{SiO}_{2}$ material film was deposited over a bulk silicon substrate followed by a $40 \mathrm{~nm}$ thick $\mathrm{Si}_{3} \mathrm{~N}_{4}$ material, using PECVD. Some specific process conditions are listed in Table 2.

\section{Results and discussion}

\subsection{Characterization of the new copolymer PS- $b$-PC}

Gel permeation chromatography (GPC) of the sample (PS- $b$-PC) was conducted with an Agilent Technologies 1260 Infinity II. The molar ratio of PS to PC is close to $1: 1$ by GPC, as shown in Fig. 1(a). And then, both NMR and TGA tests further confirm that the PS to PC ratio of the copolymer is close to $1.39: 1$, as shown in Fig. 1(b) and (c).

Previous investigation shows that ordered phase separation can be easily realized if the PS content in a diblock copolymer (PS- $b$-X) is controlled in the range of $53-72 \%$. Beyond that range, more defects will be observed in self-assembled patterns, and even, to some extent, the phase separation will disappear completely. ${ }^{35-38}$ The molar content of PS in our diblock copolymer is $67 \%$, which is consistent with the study above. The molecular structure of our diblock copolymer is sketched in Fig. 2. An important component in the structure is the $-\mathrm{NH}-$ group which can bond with $\mathrm{Si}-\mathrm{OH}$ group on $\mathrm{Si}$ substrate to form a hydrogen bond, which plays an important role in contributing to vertical phase separation. More details will be discussed later.

Recent studies show that a practical approach to the design of high- $\chi$ BCPs is to increase either the hydrophobicity of the hydrophobic block or the hydrophilicity of the hydrophilic block in an amphiphilic BCP. As is well accepted, the relationship among the phase separation period $\left(L_{0}\right)$, Flory-Huggins parameter $(\chi)$, and the copolymer's degree of polymerization $(N)$ can be expressed as $L_{0} \approx \chi^{1 / 6} N^{2 / 3} \cdot{ }^{39}$ Since our PS- $b$-PC material has a very similar molecular structure to that of the material applied in the IBM paper, a value of $\chi$ of 0.19 from the IBM paper is suitable for our approximation calculation. ${ }^{40}$ The copolymer's degree of polymerization $(N)$ is calculated as 60 as a result. $L_{0}$ is calculated as $16.5 \mathrm{~nm}$, which is very consistent with our experimental results. Specific parameters are listed in Table 3.

Table 2 Deposition of four different substrates

(1) $\mathrm{SiO}_{2} 40 \mathrm{~nm}$

Silane flow (sccm)

$\mathrm{N}_{2}$ flow (sccm)

$\mathrm{NH}_{3}$ flow (sccm)

$\mathrm{N}_{2} \mathrm{O}$ flow (sccm)

AC power $(\mathrm{W})$

HF power $(\mathrm{W})$

Temperature $\left({ }^{\circ} \mathrm{C}\right)$

Deposition time (s)

Pressure (mtorr)

(2) $\mathrm{Si}_{3} \mathrm{~N}_{4} 40 \mathrm{~nm}$

(3) $\mathrm{SiO}_{2} 40 \mathrm{~nm} / \mathrm{Si}_{3} \mathrm{~N}_{4} 30 \mathrm{~nm}$

(4) $\mathrm{Si}_{3} \mathrm{~N}_{4} 40 \mathrm{~nm} / \mathrm{SiO}_{2} 30 \mathrm{~nm}$

\section{$5 / 20$}

$0 / 180$

$0 / 45$

$80 / 0$

$0 / 20$

$30 / 160$

$350 / 350$

$20 / 34$

$1200 / 1600$
$20 / 5$

$180 / 0$

$45 / 0$

$0 / 80$

$20 / 0$

$160 / 30$

$350 / 350$

$45 / 15$

$1600 / 1200$ 

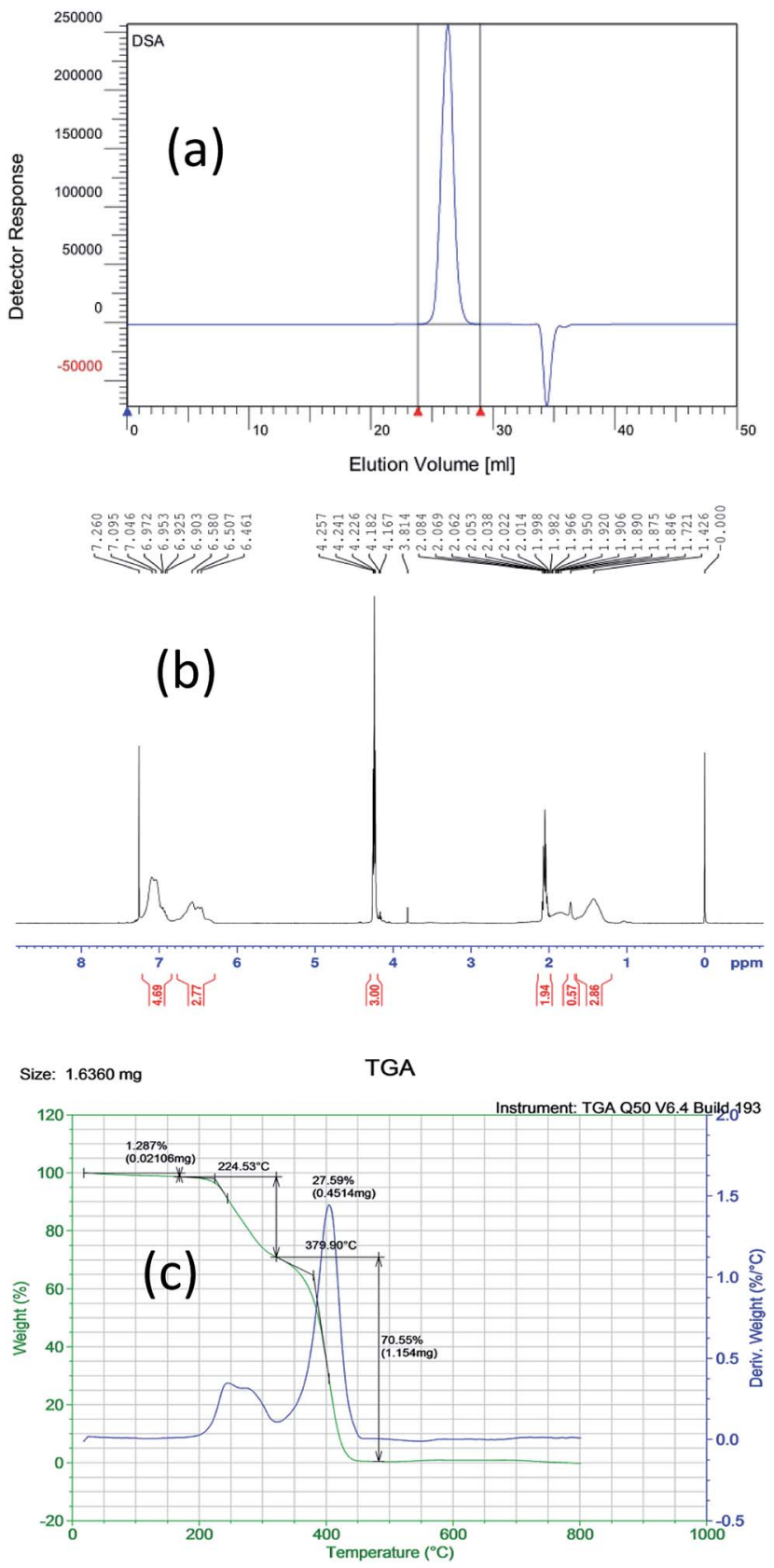

Fig. 1 Different characterization results of the new BCP (PS- $b-P C)$ based on (a) GPC, (b) NMR and (c) TGA.

\subsection{The micro-phase separation mechanism of PS- $b$-PC}

3.2.1 Water contact angle of PS- $\boldsymbol{b}$-PC. It is observed that the cleaning steps are very necessary to the phase separation. Cleaning procedure helps reduce the surface energy and<smiles>CC(=O)OCCCOC(=O)OCCNC(C)C(C)CC(C)C</smiles>

Fig. 2 Chemical structure of PS- $b-P C$. promote micro-phase separation. Phase separation is impossible to be observed after annealing as expected if wet cleaning is not applied before PS- $b$-PC spin-coating. In our experiments, water contact angle on the substrate surface is measured as $13.6^{\circ}$ before the cleaning. After the SPM and APM cleaning steps, silanol groups are formed and sample surfaces tend to be very hydrophilic. The contact angles of the samples are around $16.7 \pm 1^{\circ}$.

After spin-coating PS- $b$-PC on the surface of the silicon substrate, the polymer constituting the diblock copolymer can be thermally annealed at above the glass transition temperature of the polymer. In the process of self-assembly, atoms, molecules, particles, and other constructions are driven by the system free energy, and at the same time, the micro-phase separation spontaneously occurs and they assemble themselves into periodic structures or special functional structures. In order to verify whether the phase separation forms lamellae oriented perpendicular to the substrate, a water contact angle experiment on a silicon substrate is carried out, as shown in Fig. 3. It is clearly observed that the surface energy of PS and PC is $50.17 \mathrm{mN} \mathrm{m}^{-1}$ and $49.12 \mathrm{mN} \mathrm{m}^{-1}$, respectively. The ratio is approximately $1: 1$ indicating vertically oriented lamellae on the substrate, as shown in Fig. 3.

The PS- $b$-PC copolymer is dissolved in PGMEA with $1 \%$ solid content. The PS- $b$-PC solution is spin-coated on clean Si wafers with two spin speeds. The spin speed is set at $500 \mathrm{rpm}$ for $5 \mathrm{~s}$, and then quickly increased to $1000 \mathrm{rpm}$ for $30 \mathrm{~s}$. The film thickness is measured as about $35.2 \mathrm{~nm}$ by scanning electron microscopy (SEM) before annealing, as shown in Fig. 4(a). The substrates together with PS- $b$-PC films are baked in vacuum at different temperatures ranging from 140 to $190{ }^{\circ} \mathrm{C}$ for $10 \mathrm{~min}$. SEM images show that vertical micro-phase separation is obtained for an annealing temperature at $160-170{ }^{\circ} \mathrm{C}$ for $10 \mathrm{~min}$, as shown in Fig. 4(b) and (c). During the thermal annealing process, the mutual movement of block domains of BCP is promoted due to the existence of different surface energies for the two segments of BCP, leading to the system being more densely arranged. The film thickness after the bake is about $28.0 \mathrm{~nm}$, a reduction of about $20.5 \%$, as shown in Fig. $4(\mathrm{~d})$.

The phase separation of the new BCP is very clear, as shown in Fig. 4(c). To know more about the local structural information obtained from SEM, grazing incidence small-angle X-ray scattering (GISAXS) is used to globally probe over large sample area and the entire film depth. The first peak of the first representation is not useful; the second peak is the highest and useful; the third peak is very small and useful. Sharp diffraction peaks of the second and third position at $q_{\mathrm{y}}=0.03738 \AA^{-1}$ and $q_{\mathrm{y}}=0.0749 \AA^{-1}$ (Fig. 5(a) and (b)) indicate a fully perpendicular lamella-forming structure well corresponding to a phase period of $L_{0}=16.8 \mathrm{~nm}$, which is consistent with the SEM observations. Both SEM (Fig. 4) and GISAXS (Fig. 5) indicate that the microphase separation period is $16.8 \mathrm{~nm}$ with a good consistency between experiment and characterization.

3.2.2 Mechanism of micro-phase separation with no neutral layer. The micro-phase separation in diblock copolymers has been extensively studied from both theoretical and experimental points of view. The phase diagram of a diblock 
Table 3 New block copolymer (PS- $b-\mathrm{PC}$ ) material parameters

\begin{tabular}{lllllr}
\hline Name & $\begin{array}{l}\text { PS content } \\
(\mathrm{mol} \%)\end{array}$ & $\begin{array}{l}\text { PC content } \\
(\mathrm{mol} \%)\end{array}$ & $\begin{array}{l}\text { Molecular } \\
\text { weight } M_{\mathrm{n}}\end{array}$ & $\begin{array}{l}\text { Nuclear magnetic } \\
\text { resonance } M_{\mathrm{n}}\end{array}$ & $\begin{array}{l}\text { Glass transition } \\
\text { temperature } T_{\mathrm{g}}\end{array}$ \\
\hline $\begin{array}{l}\text { PS- } b- \\
\text { PC }\end{array}$ & 67 & 33 & 7000 & $\begin{array}{l}\text { PS(3.9k)- } b- \\
\text { PC(2.0k) }\end{array}$ & 50.8 \\
PDI
\end{tabular}

copolymer is determined by three independent factors: volume fractions of the two blocks $(f)$, the degree of polymerization of the two blocks $(N)$, and degree of incompatibility of the two blocks described by the Flory-Huggins interaction parameter $(\chi)$. In diblock copolymers, the morphology of the microdomains varies from sphere and cylinder to lamellar depending on the volume fraction of the blocks. The micro-phase separation morphology of a diblock copolymer depends on the volume fraction $(f)$ of the two blocks and degree of segregation $(\chi N) .{ }^{41}$ According to the theory of phase diagram in the thermal equilibrium state, strong segregation regime requires $\chi N>10$, where the interfaces among the phases tend to be very sharp and dissimilar and the blocks are separated into a variety of ordered periodic phase morphologies. ${ }^{41}$ For our developed PS- $b$-PC copolymer, $\chi N$ is about 11.4 , which sufficiently meets the condition of a strong segregation regime. Clearly, the mutual constraints and influences of these parameters ultimately determine the vertical phase separation structure of the novel BCP under thermal equilibrium.

As discussed above, PS- $b$-PC can easily form a vertical phase separation structure on the silicon substrate in the absence of a neutral layer. It is believed that hydrogen bonds formed by active $\mathrm{H}$ in the molecular structure binding with $\mathrm{Si}-\mathrm{OH}$ on the silicon surface $(\mathrm{NH} \cdots \mathrm{OH})$ may play an important role. ${ }^{42,43}$ The scheme of $\mathrm{Si}-\mathrm{OH}$ formation on the silicon substrate surface and
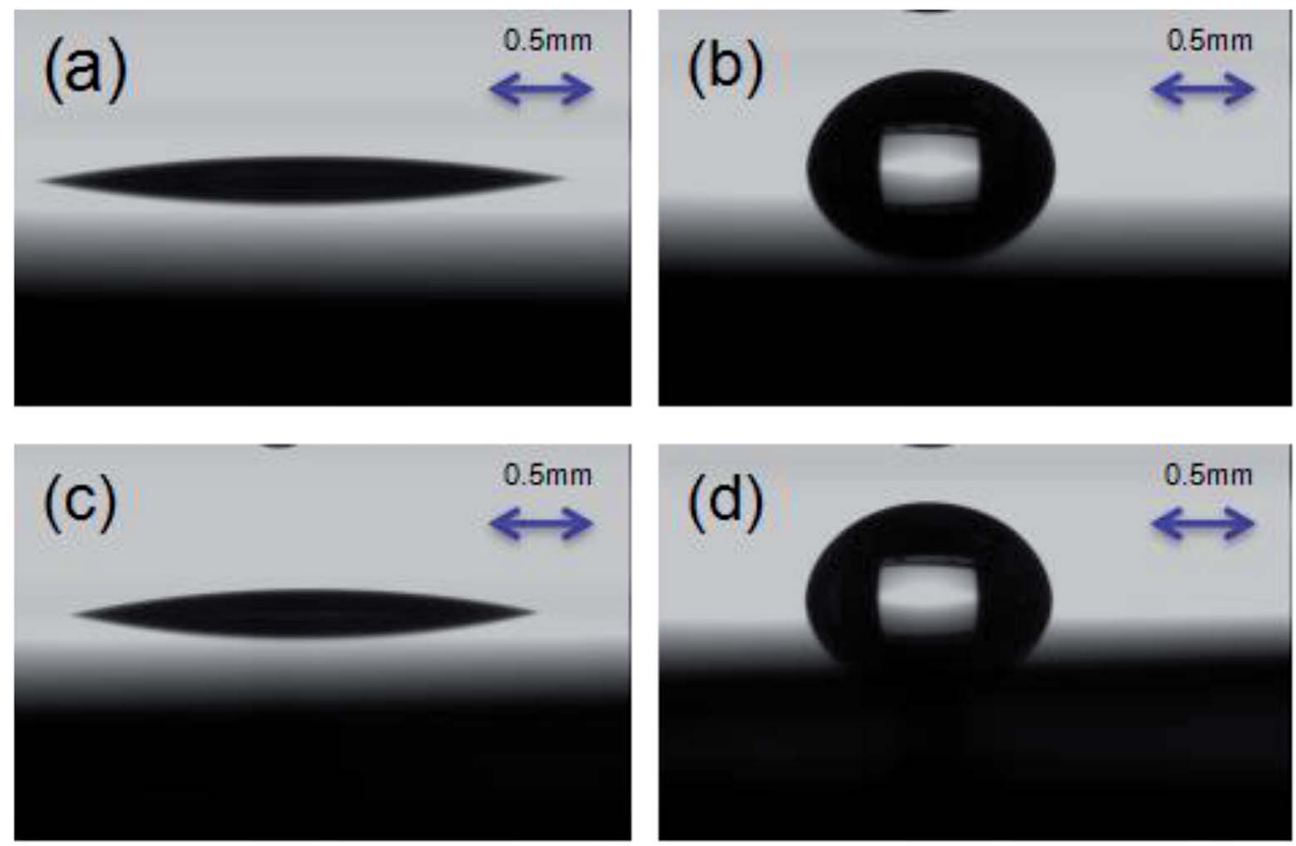

Fig. 3 (a) The PS diiodomethane contact angle is $15.8^{\circ}$. (b) The PS water contact angle is $88.6^{\circ}$. (c) The PC diiodomethane contact angle is $17.2^{\circ}$. (d) The PC water contact angle is $86.8^{\circ}$. a simplified molecular structure of the BCP (PS- $b$-PC) are shown in Fig. 6(a) and (b), respectively. The copolymer (PS- $b$-PC) reacts with the silicon hydroxyl $(-\mathrm{OH})$ groups on the silicon substrate to form hydrogen bonds which greatly contribute to the formation of a vertical micro-phase separation structure, as shown in Fig. 6(c). A schematic diagram of the hydrogen bonding mechanism is shown in Fig. 6(d). More details will be discussed later.

\subsection{The formation mechanism of hydrogen bonds}

As shown above, it is strongly believed that the active $\mathrm{H}$ plays an important role in promoting micro-phase separation of vertical structure in this work. To verify the assumption, a systematic experiment has been carried out by adding an epoxy-containing small monomer, $n$-butyl acrylate glycidyl ether, to the solution. It will react with the active $\mathrm{H}$ to form an alkyl-substituted hydroxyl group and block the active $\mathrm{H}$, as shown in Fig. 7.

In the experiment, the volume ratio of PS- $b$-PC to $n$-butyl acrylate glycidyl ether $\left(\mathrm{C}_{7} \mathrm{H}_{14} \mathrm{O}_{2}\right)$ ranges from $3: 1,2: 1,1: 1$, $1: 2,1: 3$ to $1: 5$. The mixture is firstly heated at $50{ }^{\circ} \mathrm{C}$ for $40 \mathrm{~min}$, and then placed at room temperature for 10 hours for sufficient chemical reaction. In order to exclude the influence of over-dilution on PS- $b$-PC disable micro-phase separation, undiluted $n$-butyl acrylate glycidyl ether is added directly to the copolymer (PS- $b$-PC). The experiment shows that no visible 

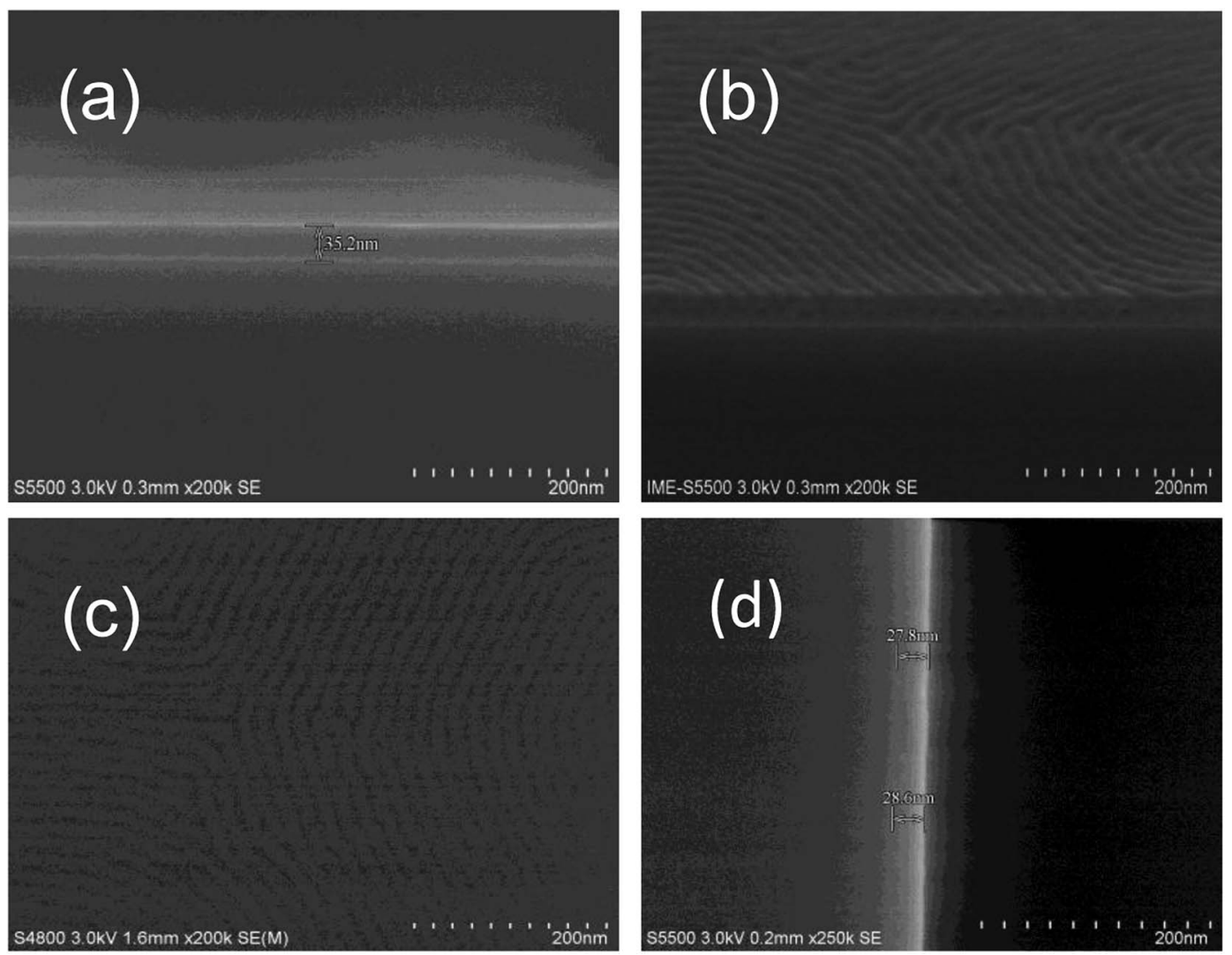

Fig. 4 (a) Cross-sectional SEM image of PS-b-PC before annealing. (b) Cross-sectional and (c) top-down SEM images of PS- $b$-PC with no neutral layer. (d) Cross-sectional SEM image of PS- $b-P C$ after annealing.

phase separation structure can be observed, even if changing the mixing rate, as shown in Fig. 7.

Hexamethyldisilazane (HMDS) treatment is a common practice to change the hydrophobicity of Si substrate surface. After HMDS treatment, Si-OH on the surface becomes - si-Osi $_{\substack{\mathrm{CH}_{3} \\ \mathrm{CH}_{3}}}^{\mathrm{CH}_{3}}$ achieving a successful transition from hydrophilic to hydrophobic. Accordingly, the water contact angle is changed from $15.4^{\circ}$ to $79.2^{\circ}$, and no vertical micro-phase separation can be observed, which could be attributed to lack of polar hydrogen bonds on the silicon surface after treatment.

In most cases, the $\mathrm{X}-\mathrm{H}$ bond is much stronger than the $\mathrm{H} \cdots \mathrm{A}$ bond (i.e. the $\mathrm{N}-\mathrm{H}$ bond in this work is much stronger than the $\mathrm{H} \cdots \mathrm{A}$ bond). However, this does not mean that the two have no
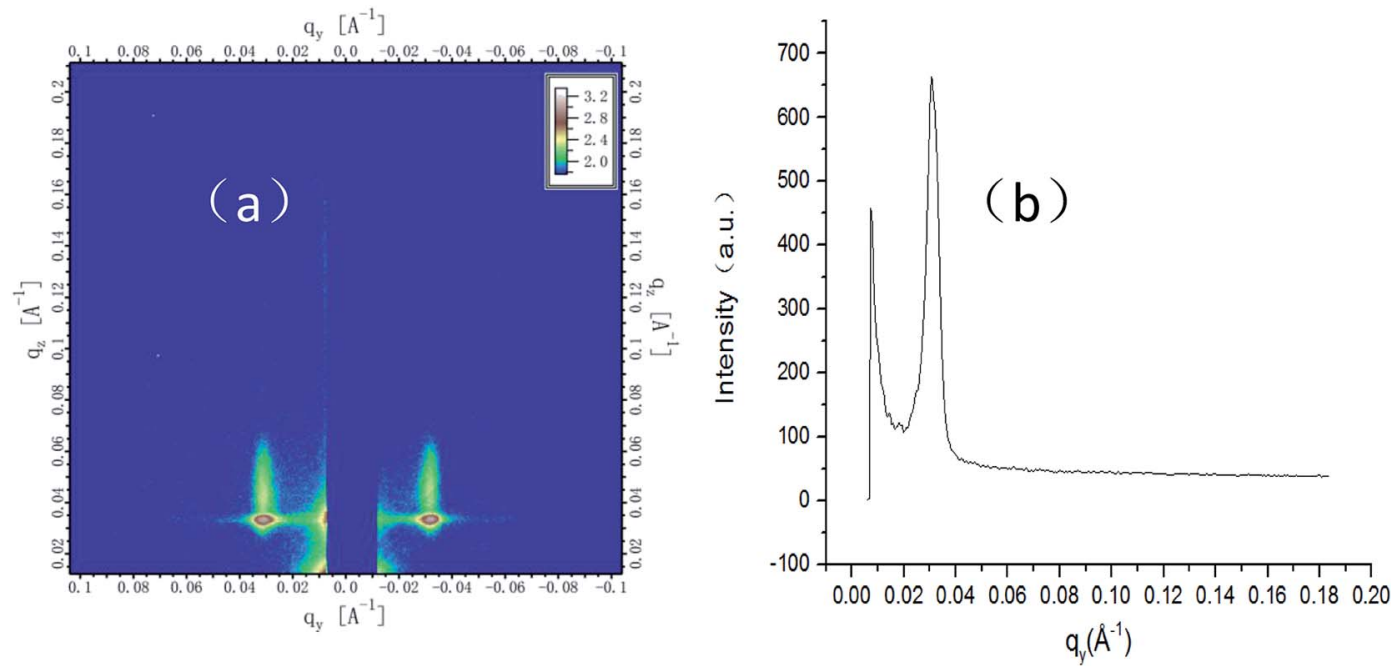

Fig. 5 (a) GISAXS pattern of PS- $b$-PC. (b) GISAXS pattern of a bulk sample of PS- $b$-PC. A vertical layered microstructure of the sample is obtained and the second peak of $q_{y}$ is $0.03718 \AA^{-1}$ for the thin film, and its phase period is $16.8 \mathrm{~nm}$. 
(a)

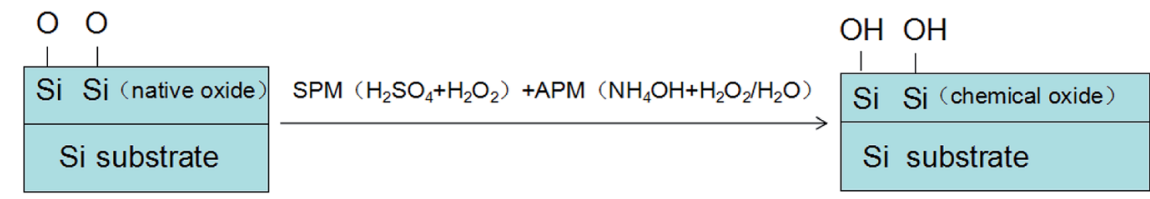

(b)

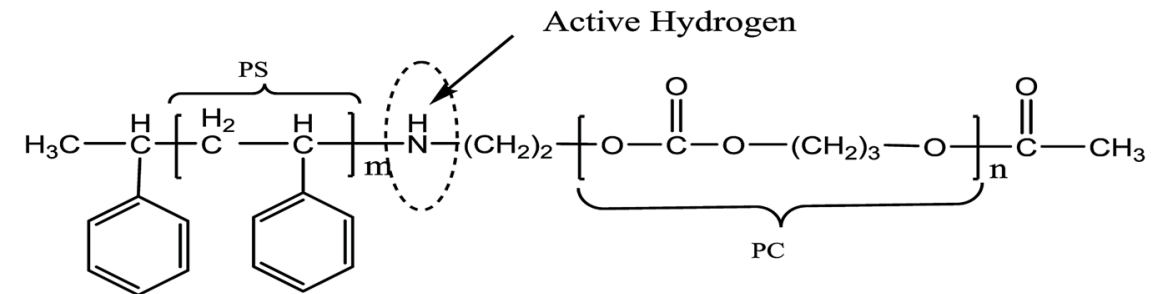

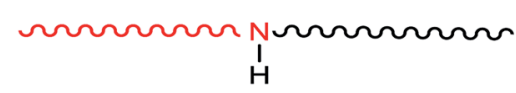

ก ก PS

ก ก PC

(c)

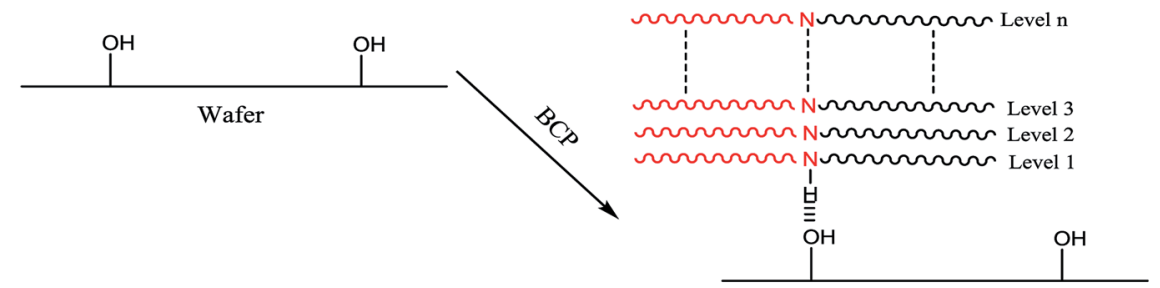

(d)

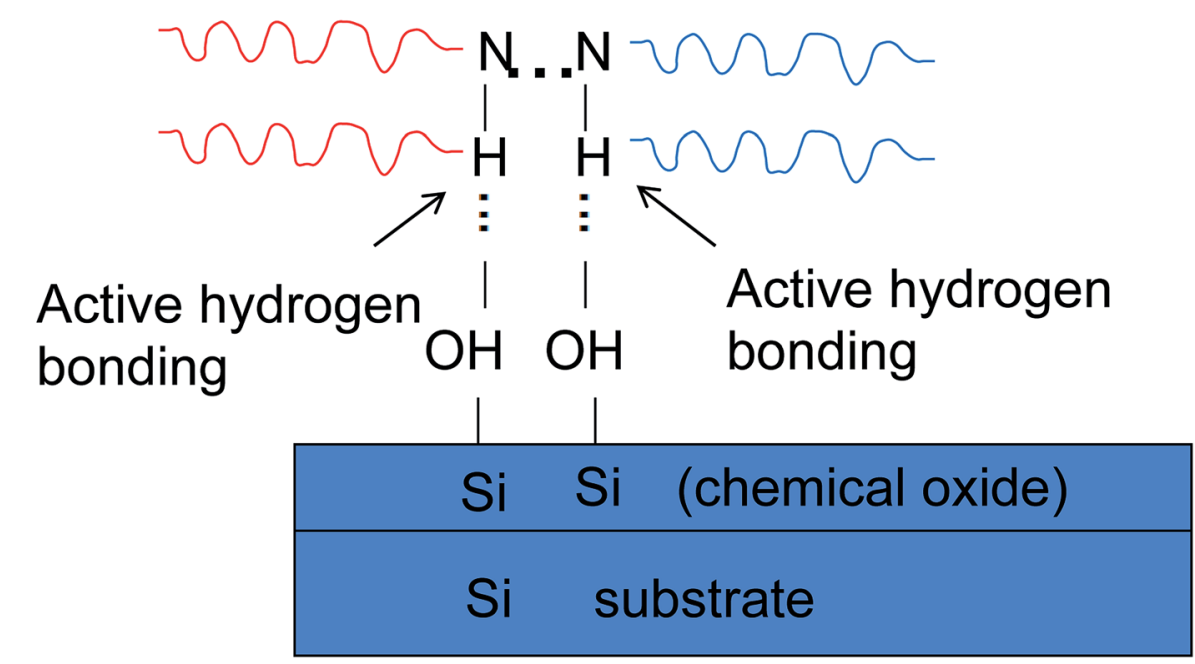

Fig. 6 (a) $\mathrm{Si}-\mathrm{OH}$ bonds are formed on the surface of the silicon substrate by appropriate wet cleaning treatment. (b) Molecular structure of the novel BCP (PS-b-PC). (c) An illustration of vertical micro-phase separation structure formation by hydrogen bonding. (d) A schematic diagram of the formation mechanism of hydrogen bonds.

effect on each other. In fact, not only do they affect each other, but other atoms or groups connected to $\mathrm{X}$ and $\mathrm{A}$ also will exert an influence. It is important to point out that a strong polar

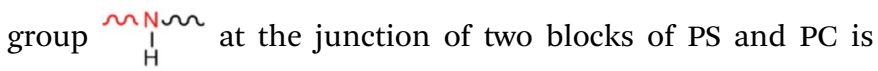
introduced intentionally in this work. The $\mathrm{N}-\mathrm{H}$ bond (donor) in the novel BCP (PS- $b$-PC) interacts with the $\mathrm{Si}-\mathrm{OH}$ bond on the silicon substrate to form a hydrogen bond anchored on the silicon substrate.

The hydrogen atoms that form hydrogen bonds must have a partial positive charge, while the hydrogen bond acceptor can be an atom, anion, molecular fragment, or molecule, as long as it has a region with high electrical charge. When the silicon substrate is cleaned in SPM + APM solution, silanol groups are easily formed on the substrate. Once PS- $b$-PC is spin-coated on the substrate, hydrogen bonds $(\mathrm{N}-\mathrm{H} \cdots \mathrm{OH})$ will be formed between the active $\mathrm{N}-\mathrm{H}$ bond and the $\mathrm{Si}-\mathrm{OH}$ bond by an appropriate annealing process. It is especially worth noting that a hydrogen bond is a unique non-covalent bonding phenomenon, with a certain degree of directionality and strength. Moreover, its formation is highly reversible and reproducible, and the process is also fast. In macromolecular chemistry, 

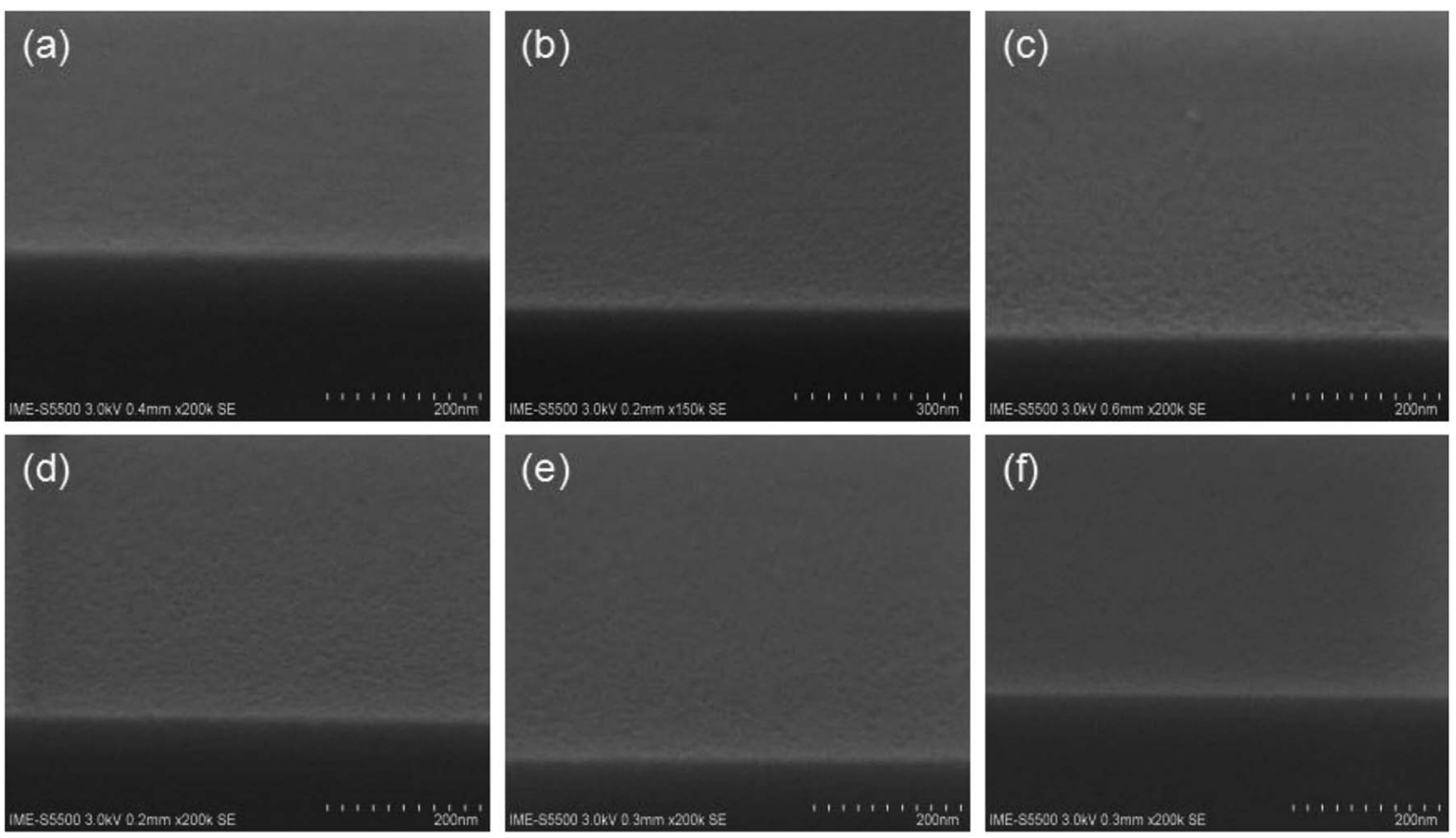

Fig. 7 SEM images of PS- $b$-PC mixed with $n$-butyl acrylate glycidyl ether after annealing and with corresponding mixing ratios of (a) $3: 1$, (b) $2: 1$, (c) $1: 1$, (d) $1: 2$, (e) $1: 3$ and (f) $1: 5$.

hydrogen bonds can control and direct the structure of molecular aggregates in the entire structure as well as some local specific sites. The directionality gives rise to selectivity and specificity to the intermolecular recognition process. For our new BCP, since the surface energies of the PS and PC blocks are almost identical, the preferential adsorption of a certain block on the substrate is unlikely. Instead, the two blocks can reach a delicate balance on the substrate. Under the influence of the hydrogen bond $(\mathrm{N}-\mathrm{H} \cdots \mathrm{OH})$ vertical lamella-forming structures can be successfully achieved in the absence of a neutral layer.

All in all, the combination of theory and experimental verification proves that the hydrogen bond is a real driving force in contributing to the formation of a periodic and lamella-forming phase separation structure, with the domains oriented perpendicular to the substrate in the absence of neutral layer by means of our specifically developed BCP material.

It is especially worthwhile noting that the schematic hydrogen bonding mechanism proposed here is a little like an uppercase letter "V", as shown in Fig. 8. For this reason, the hydrogen bond mechanism is also called the "V" model. Both ends of the "V" are PS and PC blocks at the left and right, and its bottom end is the hydrogen bond formed between silanol and $-\mathrm{NH}-$. And then, layer by layer, the perpendicular micro-phase separation structures is formed on the silicon substrate.

\subsection{Application of new PS- $b$-PC on different substrates}

As discussed above, the hydrogen bond $(\mathrm{N}-\mathrm{H} \cdots \mathrm{OH})$ plays an important role in promoting the vertical phase separation of PS$b$-PC on silicon substrates. Besides silicon substrate, the novel PS- $b$-PC copolymer was also used with some silicon-based substrate materials such as $\mathrm{SiO}_{2}$ and $\mathrm{Si}_{3} \mathrm{~N}_{4}$. Here, a few simple experiments are provided as a reference. We have investigated four different film stacks on Si substrates with no neutral layer, using annealing temperatures of each of 160 and $170{ }^{\circ} \mathrm{C}$. The four different types of film stacks are as follows: (1) $40 \mathrm{~nm}$ thick $\mathrm{SiO}_{2}$; (2) $40 \mathrm{~nm}$ thick $\mathrm{Si}_{3} \mathrm{~N}_{4}$; (3) $40 \mathrm{~nm}$ thick $\mathrm{SiO}_{2}+30 \mathrm{~nm}$ thick $\mathrm{Si}_{3} \mathrm{~N}_{4}$; (4) $40 \mathrm{~nm}$ thick $\mathrm{Si}_{3} \mathrm{~N}_{4}+30 \mathrm{~nm}$ thick $\mathrm{SiO}_{2}$. After film deposition followed by wet cleaning in SPM and APM solutions, -OH bonds will easily form on the surface. ${ }^{44-46}$ At the same time, PS- $b$-PC is spin-coated on the substrates directly without any extra process. Under the process conditions, the $\mathrm{Si}-\mathrm{OH}$ bond on the surface of $\mathrm{SiO}_{2}$ and $\mathrm{Si}_{3} \mathrm{~N}_{4}$ combines with the $-\mathrm{NH}$ - bond in the novel BCP to form a hydrogen bond, which promotes vertical phase separation, as shown in Fig. 9.

Since the present paper focuses on an investigation of microphase separation mechanism in the absence of a neutral layer, a detailed pattern transfer into the underlying substrate to

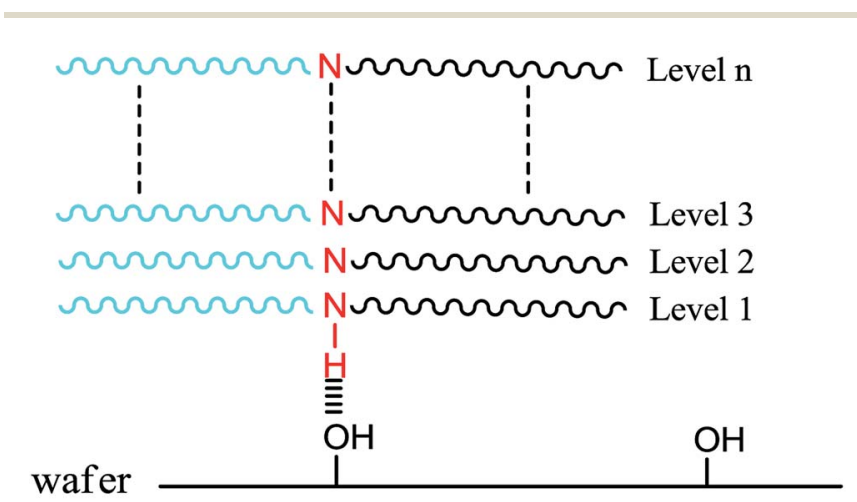

\section{Si substrate}

Fig. 8 A schematic diagram of the " $V$ " model forming a periodic and lamella-forming phase separation structure perpendicular to the substrate without a neutral layer. 


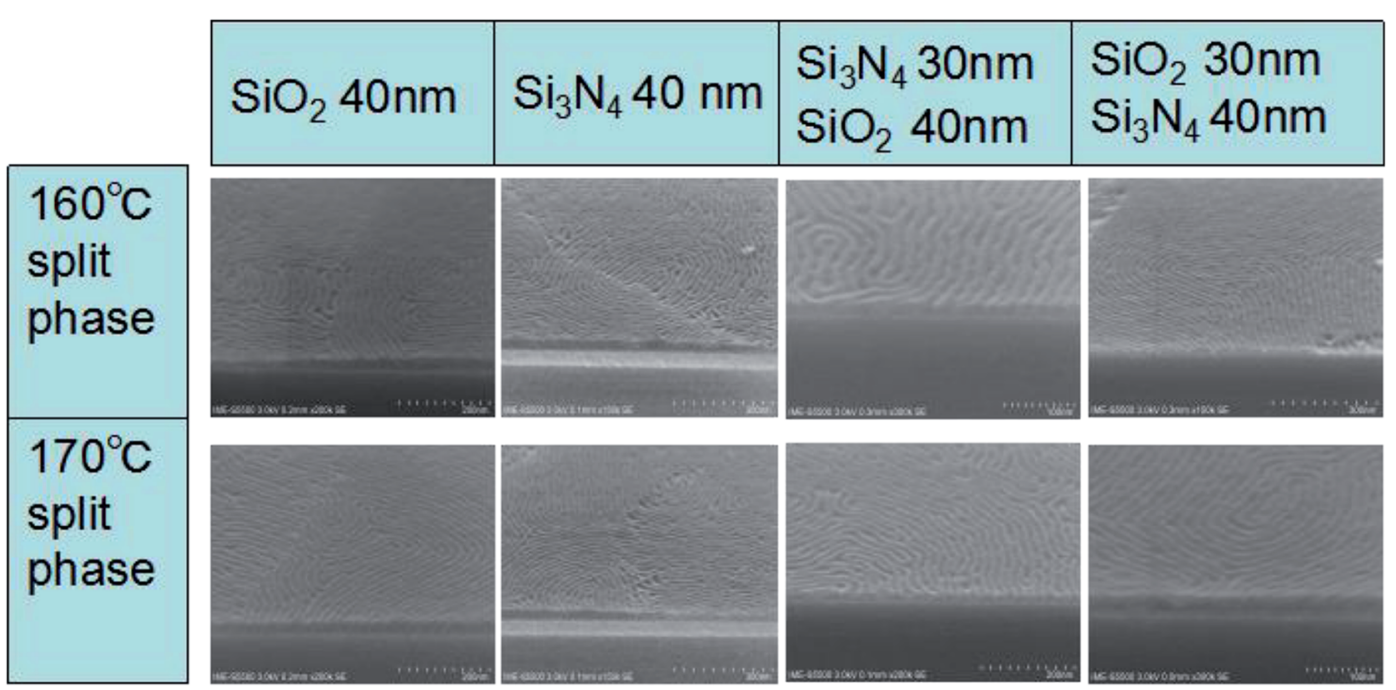

Fig. 9 SEM images of PS- $b-P C$ on four different substrates after annealing at $160{ }^{\circ} \mathrm{C}$ and $170{ }^{\circ} \mathrm{C}$.

achieve specifically designed structures is well beyond the intended scope of this work. Some related work on pattern transfer was reported in our previously published paper regarding advanced CMOS devices. ${ }^{47,48}$ Currently, a DSA-related study with no neutral layer is being carried out in different design layout trenches to achieve sub- $20 \mathrm{~nm}$ features with a long-range order, and interesting results will be further published in following papers.

\section{Conclusions}

A novel high- $\chi$ diblock copolymer (PS- $b$-PC) has been synthesized by our innovative customization. Vertical micro-phase separation with a pitch of $16.8 \mathrm{~nm}$ can be successfully achieved using only thermal annealing and a spin-coating process without any neutral layer on a Si substrate, which makes PS- $b$ PC a promising candidate for next-generation lithography. The result is mainly attributed to the hydrogen bond formed by the interaction of silanol with the active $\mathrm{H}$ in the $-\mathrm{NH}$ - group. Also, the novel PS- $b$-PC can be successfully applied on some other silicon-based substrates, such as $\mathrm{SiO}_{2}$ and $\mathrm{Si}_{3} \mathrm{~N}_{4}$, to fabricate various periodical nanostructures or functional electronic devices. The innovatively developed BCP material greatly reduces the complexity of process conditions and manufacturing costs, and is suitable for delivering large-area patterning for advanced nanofabrication. We believe that PS$b$-PC has an extremely important application value in the semiconductor industry. Simultaneously, the scope of future work will be focused on further optimization in reducing domain spacing, line edge/width roughness and process time, as well as the pattern transfer process for this kind of BCP on more interfaces of substrates.

\section{Conflicts of interest}

There are no conflicts to declare.

\section{Acknowledgements}

This work was supported by the National Science and Technology Major Project of China (2017ZX02315001-003), the Sichuan Provincial Science and Technology Program (2018G20321), the National Natural Science Foundation of China (NSFC) (61804174, 61604172), the Guizhou Province Science and Technology Talents (20185616), and the National Natural Science Foundation of China (NSFC) (61741505, 61865002). The authors thank the Integrated Circuits Advanced Process Center in the Institute of Microelectronics of Chinese Academy of Sciences (IMEICAS), and Jiangsu HanTop PhotoMaterials Co. Ltd.

\section{References}

1 C. K. Jeong, H. M. Jin, J. H. Ahn, T. J. Park and H. G. Yoo, Small, 2014, 10, 337-343.

2 A. Checco, A. Rahman and C. T. Black, Adv. Mater., 2014, 26, 886-891.

3 L. Meng, X. He, J. Gao, J. li and Y. Wei, Nanotechnology, 2015, 26, 415303.

4 L. Meng, X. He, J. Gao, J. li and Y. Wei, Nanoscale Res. Lett., 2016, 11, 505.

5 H. Tsai, J. W. Pitera, H. Miyazoe, S. Bangsaruntip, S. U. Engelmann and C. C. Liu, ACS Nano, 2014, 8, 52275232.

6 H. Yi, X. Y. Bao, R. Tiberio and H. S. Wong, Nano Lett., 2015, 15, 805 .

7 C. Cummins, D. Borah, S. Rasappa, R. Senthamaraikannan, C. Simao and A. Francone, ACS Omega, 2017, 2, 4417-4423.

8 S. M. Park, X. Liang, B. D. Harteneck, T. E. Pick, N. Hiroshiba and Y. Wu, ACS Nano, 2011, 5, 8523-8531.

9 C.-C. Liu, F. L. Lie, V. Rastogi, E. Franke, N. Mohanty, R. Farrell, H. Tsai, K. Lai, M. Ozlem, W. Cho, S. G. Jung, J. Strane, M. somervell, S. Burns, N. Felix, M. Guillorn, 
D. Hetzer, A. Ko and M. Colburn, Proc. SPIE, 2016, 9423, 94230S.

10 H. Y. Tsai, H. Miyazoe, J. Cheng, M. Brink, S. Dawes, D. Klaus, J. Buccignano, D. Sanders, E. Joseph, M. Colburn and M. Guillorn, Proc. SPIE, 2015, 9423, 942314.

11 H. Kato, Y. Seino, H. Yonemitsu, H. Sato, M. Kanno, K. Kobayashi, A. Kawwanishi, T. Imamura, M. Omura, N. Nakamura and T. Azuma, J. Photopolym. Sci. Technol., 2013, 26, 21-26.

12 M. Argoud, I. Servin, A. Gharbi, P. P. Barros, K. Jullian, M. Sanche, G. C. Maitral, S. Barnola, R. Tiron, C. Navarro, X. Chevalier, C. Nicolet, G. Fleury, G. Hadziioannou, M. Asai and C. Pieczulewski, Proc. SPIE, 2014, 9049, 904929.

13 F. S. Bates and G. H. Fredrickson, Annu. Rev. Phys. Chem., 1990, 41, 525-557.

14 S. Kim, D. O. Shin, D. G. Choi, J. R. Jeong, J. H. Mun, Y. B. Yang, J. U. Kim, S. O. Kim and J. H. Jeong, Small, 2012, 8, 1563-1569.

15 S.-J. Jeong, H.-S. Moon, J. Shin, B. H. Kim, D. O. Shin, J. Y. Kim, Y.-H. Lee, J. U. Kim and S. O. Kim, Nano Lett., 2010, 10, 3500-3505.

16 C. T. Black and O. Bezencenet, IEEE Trans. Nanotechnol., 2004, 3, 412-415.

17 Y.-H. La, E. W. Edwards, S.-H. Park and P. F. Nealey, Nano Lett., 2005, 5, 1379-1384.

18 E. Han, K. O. Stuen, M. Leolukman, C.-C. liu, P. F. Nealey and P. Gopalan, Macromolecules, 2009, 42, 4896-4901.

19 H. S. Suh, H. Kang, P. F. Nealey and K. Char, Macromolecules, 2010, 43, 4744-4751.

20 C.-C. Liu, P. F. Nealey, A. K. Raub, P. J. Hakeem, S. R. L. Brueck, E. Han and P. Gopalan, J. Vac. Sci. Technol., B: Microelectron. Nanometer Struct.-Process., Meas., Phenom., 2010, 28, C6B30.

21 M. Russel, Science, 1994, 265, 612-614.

22 M. Russel, J. Mol. Biol., 1998, 279, 485-499.

23 M. Russel, Mol. Microbiol., 2010, 5, 1607-1613.

24 M. Husemann, D. Mecerreyes, C. J. Hawker and J. L. Hedrick, Angew. Chem., Int. Ed., 1999, 38, 647-649.

25 Z. Merican, T. L. Schiller, C. J. Hawker, P. M. Fredericks and I. Blakey, Langmuir, 2007, 23, 10539.

26 Y. Kim, J. Pyun, J. M. Fréchet, C. J. Hawker and C. W. Frank, Langmuir, 2005, 21, 10444-10458.

27 I. In, Y. H. La, S. M. Park, P. F. Nealey and P. Gopalan, Macromolecules, 2008, 41, 9090-9097.
28 E. Han, K. O. Stuen, Y.-H. La, P. F. Nealey and P. Gopalan, Macromolecules, 2008, 41, 9090-9097.

29 E. Han and P. Gopalan, Langmuir, 2010, 26, 1311-1315.

30 B. E. Han, I. In, S.-M. Park, Y.-H. La, Y. Wang, P. F. Nealey and P. Gopalan, Adv. Mater., 2007, 19, 4448-4452.

31 M. Q. Li, K. Douki, K. Goto, X. F. Li, C. Coenjarts, D. M. Smilgies and C. K. Ober, Chem. Mater., 2004, 16, 3800-3808.

32 E. Han and P. Gopalan, Langmuir, 2010, 26, 1311-1315.

33 A. Vora, A. Chunder, M. Tjio, S. Balakrishman, E. Lofano, J. Cheng, D. P. Sanders, E. Hirahara, Y. Akiyama, O. Polishchuk, M. Paunescu, D. Baskaran, S. E. Hong and G. Lin, J. Photopolym. Sci. Technol., 2014, 27, 419-424.

34 A. Vora, A. Chunder, M. Tjio, T. Magbitang, E. Lofano, N. Arellano, K. Schmidt, K. Nguyen, J. Cheng and D. P. Sanders, J. Photopolym. Sci. Technol., 2015, 28, 659-662. 35 E. Han, K. O. Stuen, Y.-H. La, P. F. Nealey and P. Gopalan, Macromolecules, 2008, 41, 9090-9097.

36 E. Han and P. Gopalan, Langmuir, 2010, 26, 1311-1315.

37 D. Y. Ryu, J.-Y. Wang, K. A. Lavery, E. Drockenmuller, S. K. Satija, C. J. Hawker and T. P. Russell, Macromolecules, 2007, 40, 4296-4300.

38 E. Han, K. O. Stuen, M. Leolukman, C.-C. Liu, P. F. Nealey and P. Gopalan, Macromolecules, 2009, 42, 4896-4901.

39 G.-W. Yang, G.-P. Wu, X. X. Chen, S. S. Xiong, C. G. Arges, S. G. Ji, P. F. Nealey, X.-B. Lu, D. J. Darensbourg and Z.-K. XU, Nano Lett., 2017, 2, 1233-1239.

40 A. Vora, E. Hirahara, J. Cheng, D. Baskaran and O. Polishchuk, US Pat. US20160244557[P], 2016.

41 E. B. Gowd, M. S. Rama and M. Stamm, Nanostructures based on self-assembly of block copolymers, Springer, 2012.

42 H. Zeng, R. S. Miller, R. A. Flowers and B. Gong, J. Am. Chem. Soc., 2000, 122, 2635-2644.

43 M. Li, K. Yamato, J. S. Ferguson, K. K. Singarapu, T. Szyperski and B. Gong, J. Am. Chem. Soc., 2008, 130, 491.

44 T. A. Dang and R. Gnanasekaran, J. Vac. Sci. Technol., A, 1991, 9, 1406-1409.

45 F. Milanesi, S. Vendrame, E. Spadoni, F. Pipia and L. Livellara, Solid State Phenom., 2015, 219, 36-39.

46 J. Haisma, G. A. C. M. Spierings, T. M. Michielsen and C. L. Adema, Philips J. Res., 1995, 49, 23-46.

47 L. Meng, P. Hong and X. He, Appl. Surf. Sci., 2016, 362, 483489.

48 L. Meng and J. Yan, ECS J. Solid State Sci. Technol., 2017, 6, 23-28. 